\title{
Possible role of confounded taste stimuli in conditioned taste aversions
}

\author{
MARK D. HOLDER \\ Memorial University of Newfoundland, St. John's, Newfoundland, Canada
}

\begin{abstract}
In many publications, Sjödén, Archer, and their colleagues have studied conditioned taste aversions and found that in addition to taste, the bottle and/or spout containing a solution exerts strong control over the expression of an aversion. For example, Sjödén and Archer claim that this bottle stimulus will support a bottle-illness association even with long delays between the bottle and illness and after only a single conditioning trial. They have interpreted their results as indicating that contextual effects are important in taste-aversion learning. However, a confound in their procedure, stemming from the bottles they used, could explain their results in a simple way. Sjödén and Archer have emphasized that the bottle stimuli they used to distinguish between contexts consisted of one of two different sizes of drinking spouts, the larger of which made a clicking noise when licked. However, the larger spouts were always attached to plastic bottles and the smaller spouts were always attached to glass bottles. If discriminable tastes from the plastic bottles existed, then taste may have been inadvertently manipulated. Support for the likelihood of a plastic taste includes the seminal work on taste-aversion learning that stemmed from the serendipitous use of plastic bottles in the cage that rats were irradiated in and glass bottles in the home cages (see Garcia, McGowan, \& Green, 1972). In these early demonstrations, rats learned to avoid the taste of water in the plastic bottles but not the taste of water in the glass bottles.
\end{abstract}

Recently, Sjödén, Archer, and their colleagues have studied the role of stimuli, other than taste, that contribute to the expression of conditioned taste aversions. These authors reported that a bottle stimulus (a spout with a large opening and two stainless steel balls that produced a distinctive clicking noise during licking) could be associated with illness. They reported finding this bottle-illness association after just one or two bottle-poison pairings, even when the poison was injected 30 min after the bottle stimulus (Sjödén \& Archer, 1983). Additionally, taste was found to potentiate the bottle-illness association. Potentiation was indicated by a stronger aversion to the bottle after a taste-bottle compound was followed by poison than when the bottle alone was followed by poison. Furthermore, they report that the context, of which the bottle stimulus is an important part, strongly controls consumption after taste-illness pairings (Archer, Sjödén, \& Nilsson, 1985).

These reports involving bottle-illness associations are interesting for at least four reasons. First, the finding of potentiation is opposite to the more traditional result of overshadowing, and calls into question some aspects of current theories, including the Rescorla-Wagner model (Rescorla \& Wagner, 1972). However, potentiation is now regularly found (e.g., Clarke, Westbrook, \& Irwin,

This work was supported by Grant A1221 from the Natural Sciences and Engineering Research Council of Canada and Grants NS11618 and HD05958 from the National Institutes of Health. The author wishes to gratefully acknowledge the assistance of John Garcia. Correspondence should be addressed to Mark D. Holder, Department of Psychology, Memorial University, St. John's, NF A1B 3X9, Canada.
1979; Galef \& Osborne, 1978; Rusiniak, Hankins, Garcia, \& Brett, 1979), and its implications for learning theory have been examined (see Durlach \& Rescorla, 1980), so it will not be discussed further here. Second, most investigators in animal learning recognize that not all stimuli are equally well associated with all important events. For example, when paired with a shock, pellet size or noise acquire a stronger association to the shock than does taste, but when illness is used instead of shock, the taste acquires the stronger association (e.g., Domjan \& Wilson, 1972; Garcia, McGowan, Ervin, \& Koelling, 1968). This inequality has been referred to as cue to consequence learning. The fact that Sjödén and Archer (1983) report bottle-illness associations is not in itself surprising. However, the fact that these associations are so strong after only a few trials and with 30-min delays is surprising, because nongustatory stimuli, such as bottles, are often not so readily associated with illness. Third, stemming from the cue-to-consequence literature, a neuralbased model of learning has been developed (Garcia, Lasiter, Bermudez-Rattoni, \& Deems, 1985). This model emphasizes the anatomical separateness of the neural pathway for taste and gustatory feedback and the pathway for pain. Based on this model, the rapidity and robustness of the bottle-illness associations that Sjödén and Archer (1983) report would not be expected. Fourth, though taste is easily associated with illness, the effect of other stimuli comprising the context on illness associations has often been very small (e.g., Domjan \& Wilson, 1972; Garcia \& Koelling, 1966; Garcia et al., 1968). In other words, if, after consuming a bowl of cherries, you become ill 
and develop a cherry-illness association, you will find cherries aversive in Tokyo as well as in Deadwood, South Dakota. Sjödén and Archer's contention that the context plays an important role in illness associations differs from the conclusions of some investigators. These four reasons, particularly the last three, make it important to closely examine their studies.

After studying several reports by Sjödén, Archer, and their colleagues, I found that their work involved a confounded stimulus stemming from the equipment they used. A similar equipment-based stimulus is documented in the literature as leading to the initial finding of taste-illness associations in the laboratory (Garcia, McGowan, \& Green, 1972). In this early work, rats were placed in radiation chambers and allowed to drink from spouts attached to plastic bottles. In their home cages, they drank from glass bottles with identical spouts. Rats given radiation refused to drink water from the plastic bottes in either the home cage or the radiation chamber, but they drank water from the glass bottles in either location. In fact, when water stored in the plastic bottles for several hours was poured into the glass bottles, the rats refused to drink it. They would, however, drink irradiated water, nonirradiated water, and water that had stood in glass bottles for several hours (J. Garcia, personal communication, September 1985). Garcia and Koelling (see Garcia, McGowan, \& Green, 1972) concluded that the rats, using taste, could discriminate the water in the plastic bottles from the water in the glass bottles. More recently, Finch (1985) found that plastic bottles could operate as a taste stimulus. In his Experiment 1a, rats were given a saccharin solution in plastic drinking bottles followed by injections of lithium chloride. On other days, this group was given a banana-saccharin solution in plastic bottles followed by nothing (no injection). After several such pairings, the animals were given a two-bottle preference test. In the test, both bottles were glass: one bottle contained water poured from a plastic bottle and the other contained water from a glass bottle. Relative to a control group that had received the same experience with tastes and illness, except that the tastes and illness were given on different days, the experimental group showed an aversion to water from plastic bottles. Apparently, the plastic taste was distinct enough to rats for it not to be masked by other flavors presented during conditioning. This plastic bottle effect was observed even though the water had stood in the plastic tubes for less than $1 \mathrm{~h}$ prior to conditioning and testing, and even though the plastic taste was paired with illness on a partial-reinforcement schedule. In Finch's Experiment $1 \mathrm{~b}$, the rats were given additional saccharin-illness pairings and then six extinction trials in which the rats drank unflavored water from the plastic bottles. After extinction, the aversion to the plastic water was still significant, as measured in a two-bottle preference test. In several papers, Sjödén and Archer have repeated the plastic-glass part of this procedure. Their noise or bottle stimulus and one context were always used in conjunction with plastic bottles, whereas their silent stimulus and the other context were always used with glass bottles.

Several experiments by Sjödén, Archer, and their colleagues involve the use of plastic versus glass bottles without consideration of discriminable tastes stemming from the bottles. Just four of their publications will be reviewed here to illustrate that this confound existed and how it might have contributed to their results. The first publication concluded that the exteroceptive cues forming the context play an important role in conditioned taste aversions (Archer, Sjödén, Nilsson, \& Carter, 1979). This conclusion was based on two similar experiments (Archer, Sjödén, Nilsson, \& Carter, 1979) in which a stimulus, the taste of saccharin, and an illness-inducing agent, lithium chloride, were paired in one context and extinguished in another. When the context in which acquisition had taken place was reinstated after extinction, there was an increase in the expressed saccharin aversion, suggesting that the extinction was context specific. However, an alternative explanation of the findings of Archer, Sjödén, Nilsson, and Carter (1979) is possible. The two contexts used by Archer et al. differed not only in terms of visual, auditory, tactual, and olfactory cues, but also, quite likely, in the taste of the solution. The saccharin solution was always presented in one context in a plastic bottle and in the other context in a glass bottle. If we assume that the different bottles produced different tastes, as described earlier, then the results of Archer et al. are easily accounted for without invoking such factors as the "exteroceptive background context." According to my alternative explanation, in Archer et al.'s (1979) Experiment 1, the rats were conditioned using a saccharin-plastic taste, extinguished with a saccharin taste, and tested with a saccharin-plastic taste (the taste-context assignments were reversed with the same results for their Experiment 2). Perhaps the saccharin-plastic taste aversion was apparent in the test because the saccharin-plastic taste was never extinguished.

In another study, Sjödén and Archer (1983) reported finding a bottle-illness association after one acquisition trial even when the illness was delayed for $30 \mathrm{~min}$. They reported that, in the same series of six experiments, the strength of the bottle-illness aversion could be potentiated by taste. However, since the bottle stimulus was always used with plastic bottles and at all other times the rats drank from glass bottles, it seems possible that a plastic taste, not the bottle, was the important stimulus in this study. The "noise-illness" association, as they refer to it, might have taken longer to develop than the saccharin-illness association because the taste from the plastic bottle was weaker than the saccharin taste. Others have reported that the strength of a taste-illness association decreases as the intensity of the taste is weakened (e.g., Dragoin, 1971; Garcia, Hankins, \& Rusiniak, 1974). Perhaps Sjödén and Archer have simply redemonstrated a taste-illness association, a taste-intensity effect, and a potentiation of a weak taste by a stronger taste.

According to my analysis, in Sjödén and Archer's context-illness and noise-illness studies, the steel balls that 
clicked when licked could have been removed and the same results would have still been obtained. Two studies by Sjödén, Archer, and their colleagues show this to be the case (Archer, Sjödén, \& Carter, 1979; Archer, Sjödén, Nilsson, $\&$ Carter, 1980). In both studies, saccharin was paired with illness in one condition and extinguished in a second condition; then the saccharin aversion was measured in the original condition. The condition in which extinction took place was either the same as the one in which saccharin was paired with illness or differed with respect to one of three factors: the bottles, the compartment, or the odor. If extinction was specific to the condition it was carried out in, as indicated by the reinstatement of the aversion during the test after extinction, then the rats must have learned about the factor that distinguished the two conditions. Archer et al. (1980) concluded that rats do not learn about the odor factor but do learn about the bottle and/or compartment factor. In Experiment 1, Archer, Sjödén, and Carter (1979) found that the bottle factor, but not the compartment factor, was important. In Experiment 2, they measured the contribution of the clicking noise alone. They concluded that the clicking noise had no effect but that the plastic bottle itself was important. However, rather than considering that the plastic bottle might have contributed to the taste of the bottle stimulus, the authors concluded that the visual difference or the tongue-tactile difference between the plastic and glass bottles must be important.

I am in agreement with Sjödén and Archer on many points. For example, it has long been known that exteroceptive cues, such as brightness of walls and floor texture, can be associated with illness (e.g., Garcia, Kimeldorf, \& Hunt, 1957). However, exteroceptive cues are not always easily associated with illness and are not typically as effective as tastes (Best, Best, \& Henggeler, 1977; Best, Best, \& Mickley, 1973; Garcia, Kimeldorf, \& Hunt, 1961; Garcia \& Koelling, 1966; Garcia, Kovner, \& Green, 1970; Green, Holmstrom, \& Wollman, 1974; Hargrave \& Bolles, 1971; Larsen \& Hyde, 1977; Slotnik, Brown, \& Gelhard, 1977). Oral stimuli such as dry versus wet (Garcia, Hankins, Robinson, \& Vogt, 1972) and warm versus cool (Nachman, 1970) have also been effectively associated with illness. Animals can also learn associations between distinctive drinking spouts and illness. For example, Nachman, Rauschenberger, and Ashe (1977) reported that animals could learn aversions to different-sized drinking spouts probably because different sizes result in different oral-tactile stimulation (Nachman, personal communication, September 30, 1985). Sjödén and Archer have suggested that at the center of their work is a replication of the findings of Nachman et al. (1977). However, unlike Archer et al. (1985), I do find it difficult to refer to the oral-tactile stimulation from different-sized drinking spouts as contextual or exteroceptive stimuli. Usually, context refers only to stimuli that are present before, during, and after the conditioned stimulus. They are not uniquely correlated with the presentation of the conditioned stimulus. Of course, oraltactile stimulation from the drinking spout occurs only when the animal drinks from the spout and receives the taste stimulus.

In summary, Sjödén and Archer and their colleagues have interpreted their results as showing that, in addition to taste, exteroceptive stimuli strongly influence tasteaversion learning. However, a discriminable taste arising from the plastic bottles, which were always used with the noisy and large drinking spouts, may have allowed the rats to discriminate contexts. Although only a few publications are examined here, this discriminable-taste confound can possibly account for additional results from Sjödén and Archer's lab (Archer, Cotic, \& Järbe, 1982; Archer \& Sjödén, 1979, 1980, 1981, 1982; Sjödén \& Archer, 1981). Until these authors report similar results without the confound of the plastic taste, their interpretations remain in doubt. Additionally, the role of a plastic taste in their studies should be assessed directly by repeating a subset of their experiments with the two contexts being identical except for the plastic taste.

\section{REFERENCES}

ARChER, T., Cotic, T., \& JÄrBE, T. U. C. (1982). Attentuation of the context effect and lack of unconditioned stimulus-preexposure effect in taste-aversion learning following treatment with DSP4, the selective noradrenaline neurotoxin. Behavioral \& Neural Biology, 35, 159-173.

ARCHER, T., \& SJÖDÉN, P.-O. (1979). Neophobia in taste-aversion learning with a familiar conditioning context. Physiological Psychology, 7, 364-369.

ARCHER, T., \& SJödÉN, P.-O. (1980). Context-dependent taste-aversion learning with a familiar conditioning context. Physiological Psychology, 8, 40-46.

ARCHER, T., SJÖDÉN, P.-O. (1981). Environment-dependent taste aversion extinction: A question of stimulus novelty at conditioning. Physiological Psychology, 9, 102-108.

ARCHER, T., SJöDÉN, P.-O. (1982). Higher-order conditioning and sensory preconditioning of a taste aversion with an exteroceptive CS. Quarterly Journal of Experimental Psychology, 34B, 1-17.

ArCher, T., Suödén, P.-O., \& Carter, N. (1979). Control of tasteaversion extinction by exteroceptive cues. Behavioral \& Neural Biology, 25, 217-226.

ARCHER, T., SנöDÉN, P.-O., \& NiLSSON, L.-G. (1985). Contextual control of taste-aversion conditioning and extinction. In P. D. Balsam \& A. Tomie (Eds.), Context and learning (pp. 225-271). Hillsdale, NJ: Erlbaum.

Archer, T., Suödén, P.-O., Nilsson, L.-G., \& Carter, N. (1979). Role of exteroceptive background context in taste-aversion conditioning and extinction. Animal Learming \& Behavior, 7, 17-22.

Archer, T., Suödén, P.-O., Nirsson, L.-G., \& Carter, N. (1980). Exteroceptive context in taste-aversion conditioning and extinction: Odor, cage, and bottle stimuli. Quarterly Journal of Experimental Psychology, 32, 197-214.

Best, P. J., Best, M. R., \& HengGeler, S. (1977). The contribution of environmental non-ingestive cues in conditioning with aversive internal consequences. In L. M. Barker, M. R. Best, \& M. Domjan (Eds.), Learning mechanisms in food selection (pp. 371-393). Waco, TX: Baylor University Press.

Best, P. J., Best, M. R., \& Mickley, G. A. (1973). A conditioned aversion tu distinct environmental stimuli resulting from gastrointestinal distress. Journal of Comparative \& Physiological Psychology, $85,250-257$. 
Clarke, J. C., Westbrook, R. F., \& IrWin, J. (1979). Potentiation instead of overshadowing in the pigeon. Behavioral \& Neural Biology, 25, 18-29.

Domun, M., \& WiLson, N. E. (1972). Specificity of cue to consequence in aversion learning in the rat. Psychonomic Science, 26, 143-145.

DragoIN, W. B. (1971). Conditioning and extinction of taste aversions with variations in intensity of the CS and US in two strains of rats. Psychonomic Science, 22, 303-304.

Durlach, P., \& Rescorla, R. A. (1980). Potentiation rather than overshadowing in flavor-aversion learning: An analysis in terms of withincompound associations. Joumal of Experimental Psychology: Animal Behavior Processes, 6, 175-187.

FINCH, B. (1985). Effects of excitatory contexts on conditioned inhibition in taste aversion. Unpublished doctoral dissertation proposal, University of California at Los Angeles.

Galef, B. G., JR., \& OsBorne, B. (1978). Novel taste facilitation of the association of visual cues with toxicosis in rats. Journal of Comparative \& Physiological Psychology, 92, 907-916.

Garcia, J., Hankins, W. G., Robinson, J. H., \& VoGt, J. L. (1972). Bait shyness: Tests of CS-US mediation. Physiology \& Behavior, 8 , 807-810.

Garcia, J., Hankins, W. G., \&usiniak, K. W. (1974). Behavioral regulation of the milieu interne in man and rat. Science, 185, 824-831.

GARCIA, J., KIMELDORF, D. J., HUNT, E. L. (1957). Spatial avoidance in the rat as a result of exposure to ionizing radiation. British Journal of Radiology, 354, 318-320.

Garcia, J., Kimeldorf, D. J., \& Hunt, E. L. (1961). The use of ionizing radiation as a motivating stimulus. Psychological Review, 68, 383-395.

GARCIA, J., \& KoELLING, R. A. (1966). Relation of cue to consequence in avoidance learning. Psychonomic Science, 4, 123-124.

Garcia, J., Kovner, R., \& Green, K. F. (1970). Cue properties vs. palatability of flavors in avoidance learning. Psychonomic Science, 20, 313-314

Garcia, J., Lasiter, P. S., Bermudez-Rattoni, F., \& Deems, D. A (1985). A general theory of aversion learning. In N. S. Braveman \& P. Bronstein (Eds.), Experimental assessments and clinical application of conditioned food aversions (pp. 8-21). New York: New York Academy of Sciences.

Garcia, J., McGowan, B. K., Ervin, F. R., Koelling, R. A.
(1968). Cues: Their relative effectiveness as a function of the reinforcer. Science, 160, 794-795.

Garcia, J., McGowan, B. K., \& Green, K. F. (1972). Biological constraints on conditioning. In A. H. Black \& W. F. Prokasy (Eds.), Classical conditioning: II. Current research and theory (pp. 21-43). New York: Appleton-Century-Crofts.

Green, K. F., Holmstrom, L. S., \& Wollman, M. A. (1974). Relation of cue to consequence in rats: Effects of recuperation from illness. Behavioral Biology, 10, 491-503.

Hargrave, G. E., \& Bolles, R. C. (1971). Rat's aversion to flavors following induced illness. Psychonomic Science, 23, 91-92.

Larsen, J. D., Hyde, T. S. (1977). A comparison of learned aversions to gustatory and exteroceptive cues in the rat. Animal Learning \& Behavior, 5, 17-20.

Nachman, M. (1970). Learned taste and temperature aversions due to lithium chloride sickness after temporal delays. Joumal of Comparative \& Physiological Psychology, 73, 22-30.

Nachman, M., Rauschenberger, J., \& Ashe, J. H. (1977). Studies of learned aversions using nongustatory stimuli. In L. M. Barker, M. R. Best, \& M. Domjan (Eds.), Learning mechanisms in food selection (pp. 395-417). Waco, TX: Baylor University Press.

Rescorla, R. A., \& Wagner, A. R. (1972). A theory of Pavlovian conditioning: Variation in the effectiveness of reinforcement and nonreinforcement. In A. H. Black \& W. F. Prokasy (Eds.), Classical conditioning: 1I. Current research and theory (pp. 64-99). New York: Appleton-Century-Crofts.

Rusiniak, K. W., Hankins, W. G., Garcia, J., \& Brett, L. (1979). Flavor-illness aversions: I. Potentiation of odor by taste in rats. $B e$ havioral \& Neural Biology, 23, 1-17.

SJöDÉN, P.-O., \& ARCHER, T. (1981). Associative and nonassociative effects of exteroceptive context in taste-aversion conditioning with rats. Behavioral \& Neural Biology, 33, 74-92.

SJöDÉN, P.-O., ARCHER, T. (1983). Potentiation of a bottle aversion by taste in compound conditioning with rats. Experimental Animal Behaviour, 2, 1-18.

Slotnick, B. M., Brown, D. L., \& Gelhard, R. (1977). Contrasting effects of location and taste cues in illness-induced aversion. Physiology \& Behavior, 18, 333-335.

(Manuscript received April 12, 1985; revision accepted for publication October 20, 1986.) 